\title{
Delineating the Molecular Events Underlying Development of Prostate Cancer Variants with Neuroendocrine/Small Cell Carcinoma Characteristics
}

\author{
Mayuko Kanayama * and Jun Luo
}

Citation: Kanayama, M.; Luo, J. Delineating the Molecular Events Underlying Development of Prostate Cancer Variants with Neuroendocrine/Small Cell Carcinoma Characteristics. Int. J. Mol. Sci. 2021, 22, 12742. https:// doi.org/10.3390/ijms222312742

Academic Editor: Hiroshi Miyamoto

Received: 6 October 2021

Accepted: 19 November 2021

Published: 25 November 2021

Publisher's Note: MDPI stays neutral with regard to jurisdictional claims in published maps and institutional affiliations.

Copyright: (c) 2021 by the authors. Licensee MDPI, Basel, Switzerland. This article is an open access article distributed under the terms and conditions of the Creative Commons Attribution (CC BY) license (https:/ / creativecommons.org/licenses/by/ $4.0 /)$.
Department of Urology, James Buchanan Brady Urological Institute, Johns Hopkins University School of Medicine, Baltimore, MD 21205, USA; jluo2@jhmi.edu

* Correspondence: mkanaya1@jhmi.edu; Tel.: +1-4432872303

\begin{abstract}
The treatment landscape of prostate cancer has changed dramatically following the advent of novel systemic therapies, most of which target the androgen receptor (AR). Agents such as abiraterone, enzalutamide, apalutamide, darolutamide were designed to further suppress androgen receptor signaling following gonadal suppression achieved by first-line androgen deprivation therapies. These potent AR targeting agents are increasingly used in the earlier stages of the disease spectrum with the goal of delaying disease progression and extending survival. Although these therapies are effective in controlling prostate tumors dependent on or addicted to AR signaling, prostate tumors surviving the onslaught of potent treatments may evolve and develop drug resistance. A substantial proportion of treatment failures can be explained by the development of treatment-induced aggressive prostate cancer variants such as neuroendocrine/small cell carcinoma. These emerging disease entities demand detailed characterization and precise definitions. We postulate that these treatment-induced prostate cancer entities should be defined molecularly to overcome the drawbacks associated with the current clinical and pathological definitions. A precise molecular definition conforms with current knowledge on the molecular evolution of this disease entity and will enable early detection and early intervention.
\end{abstract}

Keywords: lineage plasticity; neuroendocrine/small cell carcinoma; aggressive variant prostate cancer

\section{Introduction}

Most treatment-naïve prostate cancers (PCa) depend on androgen receptor (AR) signaling to proliferate. Therefore, androgen deprivation therapy (ADT) (e.g., luteinizing hormone agonist/antagonist with or without casodex) is historically the first choice of treatment for advanced castration-sensitive PCa (CSPC). However, treated patients eventually develop resistance to first-line ADT and progress to castration-resistant PCa (CRPC). A subset of CRPC may progress to lethal AR-indifferent neuroendocrine/small cell carcinoma (NE/SC) following further AR suppression by the second and third-generation AR inhibitors (e.g., abiraterone, enzalutamide, apalutamide, darolutamide). A recent study showed that up to $17 \%$ of CRPC patients undergoing treatment with abiraterone/enzalutamide have histologically discernable NE/SC lesions on biopsies [1]. Emerging data suggest that PCa utilizes lineage plasticity to their advantage to evade selective pressure imposed by these potent AR-targeting agents [2]. Lineage plasticity generally describes the ability of living organisms to express variable phenotypes depending on surrounding environments. In this context, lineage plasticity involves phenotypic conversion that enables prostate cancer cells to survive in androgen-deprived conditions and obtain NE/SC characteristics.

While there have been efforts in standardizing histological diagnostic categorization for de novo as well as treatment-induced prostate cancer variants with NE/SC characteristics [3], some CRPC tumors that lost AR dependence may not show typical morphological and immunohistochemical characteristics. In addition, histology-based definition does not 
exist for CRPC tumors in a transition state to be "full-fledged" NE/SC, primarily due to histological continuum characterized by the mixed and overlapping morphologies and intra-patient and intra-tumor heterogeneity. Lineage plasticity may also compromise the ability to define these tumors. Yet, there is a clinical need to definitively characterize the subset of CRPC in the transition state to NE/SC due to their treatment implications. Identification of prostate tumors in transition to NE/SC will enable early detection and early intervention. From clinical perspective, the concept of "Aggressive variant prostate cancer" (AVPC) has been proposed to enable early detection [4,5]. One potential drawback of this AVPC criteria is that AVPC cannot be defined until relatively late stages of the disease unless patients have histologically confirmed NE/SC. Given these drawbacks of the pathological and clinical definitions, one may wonder whether detection of the molecular drivers that may occur prior to pathological and clinical manifestations could further refine existing definitions, so that NE/SC or other resistance phenotypes can be captured/detected in the transition state rather than at the end of the spectrum. In this review, we aim to summarize temporal delineation of the molecular events during the NE/SC development and discuss the potential of utilizing molecular definition to complement existing pathological and clinical definitions. This collective definition will allow precision therapy and may drive efforts in early detection (noninvasive methods, or imaging methods taking advantage of $\mathrm{NE}$ /SC markers) and early escalation treatments.

\section{Pathological Definition of Prostate Cancer Variants with NE/SC Characteristics}

We would like to first visit the existing definitions of prostate cancer variants with NE/SC characteristics. According to the 2016 WHO (World Health Organization) Classification, prostate tumors with neuroendocrine differentiation (NED) are classified into the following four categories: adenocarcinoma with NED, well-differentiated neuroendocrine tumor (carcinoid), small cell neuroendocrine carcinoma and large cell neuroendocrine carcinoma [6]. However, another version of classification has been proposed by Epstein et al. considering the unique aspects of NED in PCa. Based on their classification, prostate neuroendocrine tumors fall into the following six categories: (i) usual prostate adenocarcinoma with NED; (ii) adenocarcinoma with Paneth cell NED; (iii) carcinoid tumor; (iv) small cell carcinoma; (v) large cell neuroendocrine carcinoma; and (vi) mixed (small or large cell) neuroendocrine carcinoma-acinar adenocarcinoma [3] (Table 1). Among them, (i) and (ii) are molecularly distinct from (iv) in that (i) and (ii) did not differ by prevalence of TP53 missense mutations, or PTEN or RB1 loss when compared with those without NED, as recently reported by Kaur et al. [7]. Furthemore, (i) and (ii) are less likely to be associated with adverse clinical outcomes $[7,8]$. Thus, although further studies are needed, (i) and (ii) probably should be considered as the different disease entity from (iv) which is associated with aggressive phenotypes. In addition, (iii) and (v) are extremely rare variants and yet to be fully characterized. Therefore, to avoid confusion, the term "NE/SC" used in this review will specifically refer to (iv) small cell carcinoma or components of small cell carcinoma in (vi), whereas NEPCa (neuroendocrine prostate cancer) collectively refers to prostate cancers with NED listed in Table 1. In addition, we kept the original terminology in cited papers, although many preclinical studies did not involve diagnostic definitions.

Table 2 summarizes a set of IHC markers used for NEPCa diagnosis, some of which are exploratory markers such as Cyclin D1, YAP1, and FoxA2. NEPCa usually does not express markers generally specific to prostate cells (e.g., PSA), but characteristically expresses markers of neural lineage such as chromogranin A, synaptophysin, TTF-1 and CD56 (Table 2). Using a combination of markers improves diagnostic accuracy of NEPCa [9,10]. It is worth emphasizing that not all CRPC that lost AR dependence can be identified by morphology in conjunction with IHC. Other morphologies in the transition state are difficult to evaluate due to histological continuum characterized by the mixed and overlapping morphologies and intra-patient/intra-tumor heterogeneity. Characterization of these transitional morphologies will be discussed in Section 6 of this review. 
Table 1. The classification of neuroendocrine prostate cancer proposed by Epstein et al. [3] and WHO [6].

\begin{tabular}{c} 
Epstein's Classification \\
\hline (i) Usual prostate adenocarcinoma \\
with NE differentiation
\end{tabular}

2016 WHO Classification

Adenocarcinoma with neuroendocrine differentiation

Morphologically typical acinar or ductal prostate adenocarcinoma with NED only demonstrated by IHC. This type of tumor is molecularly and clinically distinct form (iv) small cell carcinoma and is not associated with poor outcomes [7].

Histologically typical prostate adenocarcinoma

(ii) Adenocarcinoma with Paneth cell NE differentiation

Not defined containing varying proportions of cells with prominent eosinophilic cytoplasmic granules that are chromogranin positive and contain neurosecretory granules. Similar to (i), this type of tumor is molecularly distinct from (iv)

[7], and is not associated with poor outcomes [8].

(iii) Carcinoid tumor
Well-differentiated neuroendocrine tumor

Well-differentiated NEPCa not closely associated with usual PCa. which are positive for NE markers and negative for PSA. This type of NEPCa is extremely rare and only reported in a limited number of case reports.

The most well-studied aggressive NEPCa variant that usually arises under selective pressure of ADT (can arise de novo but rare). Defined by characteristic nuclear

(iv) Small cell carcinoma

Small cell neuroendocrine carcinoma features, including lack of prominent nucleoli, nuclear molding, fragility, and crush artifact. High N/C ratio, indistinct cell borders, a high mitotic rate and apoptotic bodies are common.

An extremely rare NEPCa variant characterized by large nests with peripheral palisading and often geographic necrosis, prominent nucleoli, vesicular clumpy chromatin, and/or large cell size and abundant

(v) Large cell NE carcinoma Large cell neuroendocrine
carcinoma cytoplasm, a high mitotic rate. Positive for at least one NE marker by IHC. The largest series of seven cases was reported in 2006 [11].

Biphasic carcinoma with admixed components of NE (small cell or large cell) carcinoma and usual

(vi) Mixed (small or large cell) NE carcinoma-acinar adenocarcinoma
Not defined conventional acinar adenocarcinoma. This type of NEPCa is associated with high-grade aggressive disease. Less frequently, it shows overlap between (iv) small cell carcinoma and adenocarcinoma and is considered to be in the process of transdifferentiation.

Abbreviations: WHO-World Health Organization, NE-neuroendocrine, NED-neuroendocrine differentiation, IHCimmunohistochemistry, NEPCa—neuroendocrine prostate cancer, N/C—nuclear to cytoplasmic.

Table 2. A list of IHC markers used for NEPCa diagnosis.

\begin{tabular}{ccc}
\hline & Marker & Description \\
\hline & PSA & $\begin{array}{c}\text { PSA expression is positive throughout disease progression from } \\
\text { CSPC to CRPC [12], but positivity decreases in NE/SC [9,10,12]. } \\
\text { Yet, a subset of NE/SC (19\%) is positive PSA [10]. }\end{array}$ \\
\cline { 2 - 3 } Negative/low in NEPCa & AR & $\begin{array}{c}\text { AR transcriptional activity is low in NE/SC [1]. AR “null” mCRPC } \\
\text { is enriched with TP53, RB1 and PTEN alterations [13]. }\end{array}$ \\
\cline { 2 - 3 } & Nkx 3.1 & $\begin{array}{c}\text { Nkx 3.1 is a highly sensitive and specific prostate adenocarcinoma } \\
\text { marker [14], and has recently been the most frequently used } \\
\text { prostate marker. }\end{array}$ \\
\cline { 2 - 3 } & PSAP & PSAP expression is positively correlated with PSA expression [15]. \\
\hline
\end{tabular}


Table 2. Cont.

\begin{tabular}{|c|c|c|}
\hline & Marker & Description \\
\hline & P501s (prostein) & $\begin{array}{l}\text { P501s positivity in NE/SC is } 28 \% \text { [10]. P501s is useful in identifying } \\
\text { the prostatic origin of NE/SC than PSA [10]. }\end{array}$ \\
\hline & Cyclin D1 & $\begin{array}{c}\text { Cyclin D1 loss was observed in } 88 \% \text { of NE/SC and its loss was } \\
\text { highly correlated with Rb loss [16]. }\end{array}$ \\
\hline & YAP1 & $\begin{array}{c}\text { YAP1 is increased in high-grade adeno PCa, but downregulated in } \\
\text { NEPCa. Downregulation of YAP1 in NEPCa has been shown in } \\
\text { several datasets [17]. }\end{array}$ \\
\hline \multirow{7}{*}{ Positive in NEPCa } & Chromogranin A & $\begin{array}{c}\text { Secretory granules produced by a variety of neural cells [18]. It can } \\
\text { be used as a serum marker, too [19]. More than } 60 \% \text { of NEPCa is } \\
\text { reported to be positive for CGA }[9,10] .\end{array}$ \\
\hline & Synaptophysin & $\begin{array}{l}\text { A vesicle membrane protein that localizes in a variety of neural } \\
\text { cells [20]. More than } 80 \% \text { of NEPCa is reported to be positive for } \\
\text { SYP }[9,10] \text {. }\end{array}$ \\
\hline & $\begin{array}{l}\text { CD56 (Neural cell adhesion } \\
\text { molecule) }\end{array}$ & $\begin{array}{l}\text { Membrane-bound glycoprotein predominantly expressed in neural } \\
\text { cells. Although positivity in NEPCa is high }[9,10] \text {, its specificity is } \\
\text { low [21]. }\end{array}$ \\
\hline & $\begin{array}{l}\text { TTF-1 (Thyroid transcription } \\
\text { factor-1) }\end{array}$ & $\begin{array}{l}\text { TTF-1 is a highly sensitive marker for extrapulmonary small cell } \\
\text { carcinoma including NE/SC }[9,22] \text {. }\end{array}$ \\
\hline & FoxA2 & $\begin{array}{l}\text { A transcription factor specifically upregulated in NE/SC. Its } \\
\text { positivity is reportedly higher than CGA or SYP in NE/SC [23]. }\end{array}$ \\
\hline & $\begin{array}{l}\text { INSM1 } \\
\text { (Insulinoma-associated } \\
\text { protein 1) }\end{array}$ & $\begin{array}{l}\text { Zinc-finger transcriptional factor elevated in NE/SC [24]. INSM1 is } \\
\text { reported to be superior to CGA, SYP and CD56 [24,25]. }\end{array}$ \\
\hline & Ki67 & $\begin{array}{c}\text { A well-known marker of proliferation. Ki67 is }>50-80 \% \text { in NE/SC } \\
\text { and LC NE carcinoma but usually not increased in other tumor } \\
\text { types such as adenocarcinoma with Paneth cell NED and carcinoid } \\
\text { tumor [3]. }\end{array}$ \\
\hline
\end{tabular}

Abbreviations: PSA — prostate-specific antigen, AR—androgen receptor, mCRPC—metastatic castration-resistant prostate cancer, PSAPprostatic acid phosphatase, CGA-Chromogranin A, SYP_Synaptophysin, LC NE carcinoma-large cell NE carcinoma.

\section{Clinical Characteristics of Prostate Cancer Variants with NE/SC Characteristics}

Clinical characteristics of NE/SC are quite different from that of CRPC adenocarcinoma, and they are often exemplified by low serum PSA, high serum NE markers (e.g., chromogranin A, neuron-specific enolase), visceral metastasis, and poor response to ARtargeted therapies [26]. Traditionally, NE/SC would be clinically suspected in patients presenting with rapidly progressive disease [27]. Recently, Aparicio et al. proposed an innovative concept of aggressive variant prostate carcinoma (AVPC) as inclusion criteria for platinum-based chemotherapy trials [4] (Table 3). Indeed, patients with AVPC showed a high response rate to platinum-containing chemotherapies [4]. Furthermore, in their subsequent study, clinically defined AVPC has been proven to share molecular features with NE/SC such as RB1 loss and TP53 loss-of-function mutations [28]. Together, AVPC criteria enabled identification of patients with clinical features of NE/SC without biopsies and is currently utilized for patients selection in clinical trials [29]. However, like pathological definitions, one potential drawback of the AVPC criteria is that AVPC cannot be defined until relatively late stages of the disease when clinical characteristics listed in Table 3 become prominent. Therefore, defining the molecular events occurring prior to pathological and clinical manifestations could enable detection of NE/SC at earlier stages rather than at the end of the disease spectrum. To this end, we will summarize and discuss the molecular events underlying NE/SC development in the remaining sections of the review. 
Table 3. Clinical features of AVPC proposed by Aparicio et al. [4].

CRPC with at Least One of the Following (Patients with Small-Cell Prostate Carcinoma on Histologic Evaluation Were Not Required to Have Castration-Resistant Disease):

- $\quad$ Histologic evidence of small-cell prostate carcinoma (pure or mixed).

- Exclusively visceral metastases.

- $\quad$ Radiographically predominant lytic bone metastases by plain x-ray or CT scan.

- $\quad$ Bulky $(\geq 5 \mathrm{~cm})$ lymphadenopathy or bulky $(\geq 5 \mathrm{~cm}$ ) high-grade (Gleason $\geq 8)$ tumor mass in prostate/pelvis.

- $\quad$ Low PSA $(\leq 10 \mathrm{ng} / \mathrm{mL})$ at initial presentation (before ADT or at symptomatic progression in the castrate setting) plus high volume $(\geq 20)$ bone metastases.

- $\quad$ Presence of neuroendocrine markers on histology (positive staining of chromogranin A or synaptophysin) or in serum (abnormal high serum levels for chromogranin A or GRP) at initial diagnosis or at progression. Plus any of the following in the absence of other causes:

- $\quad$ A. elevated serum LDH $(\geq 2 \times$ IULN)

- $\quad$ B. malignant hypercalcemia

- $\quad$ C. elevated serum CEA $(\geq 2 \times$ IULN).

- Short interval ( $\leq 6$ months) to androgen-independent progression following the initiation of hormonal therapy with or without the presence of neuroendocrine markers.

Abbreviations: GRP—gastrin-releasing peptide, IULN—Institutional Upper Limit of Normal, LDH—Lactate dehydrogenase, CEA—carcinoembryonic antigen. Modified from [4].

\section{Loss of TP53 and RB1 Is a Backbone of NE/SC Development}

At the genomic level, there is a substantial overlap of genomic alterations between CRPC adenocarcinoma and NE/SC [30]. Next-generation sequencing of patient-derived specimens revealed that a loss of RB1 (a gene encoding RB protein) and TP53 (a gene encoding p53 protein) is a common denominator of genomic aberrations in NE/SC [1,30], although TP53/RB1 loss also occurs in CRPC adenocarcinoma at lower frequency [1]. Given a dynamic phenotypic switch from adenocarcinoma to NE/SC, it is critical to determine the extent to which TP53/RB1 loss is responsible for NE/SC development. In fact, a large proportion of molecular events underlying NE/SC development may be explained by ramifications of TP53 and RB1 inactivation as we discuss below. Figure 1 illustrates the molecular events underlying development of NE/SC to be discussed in the remaining sections of the review.

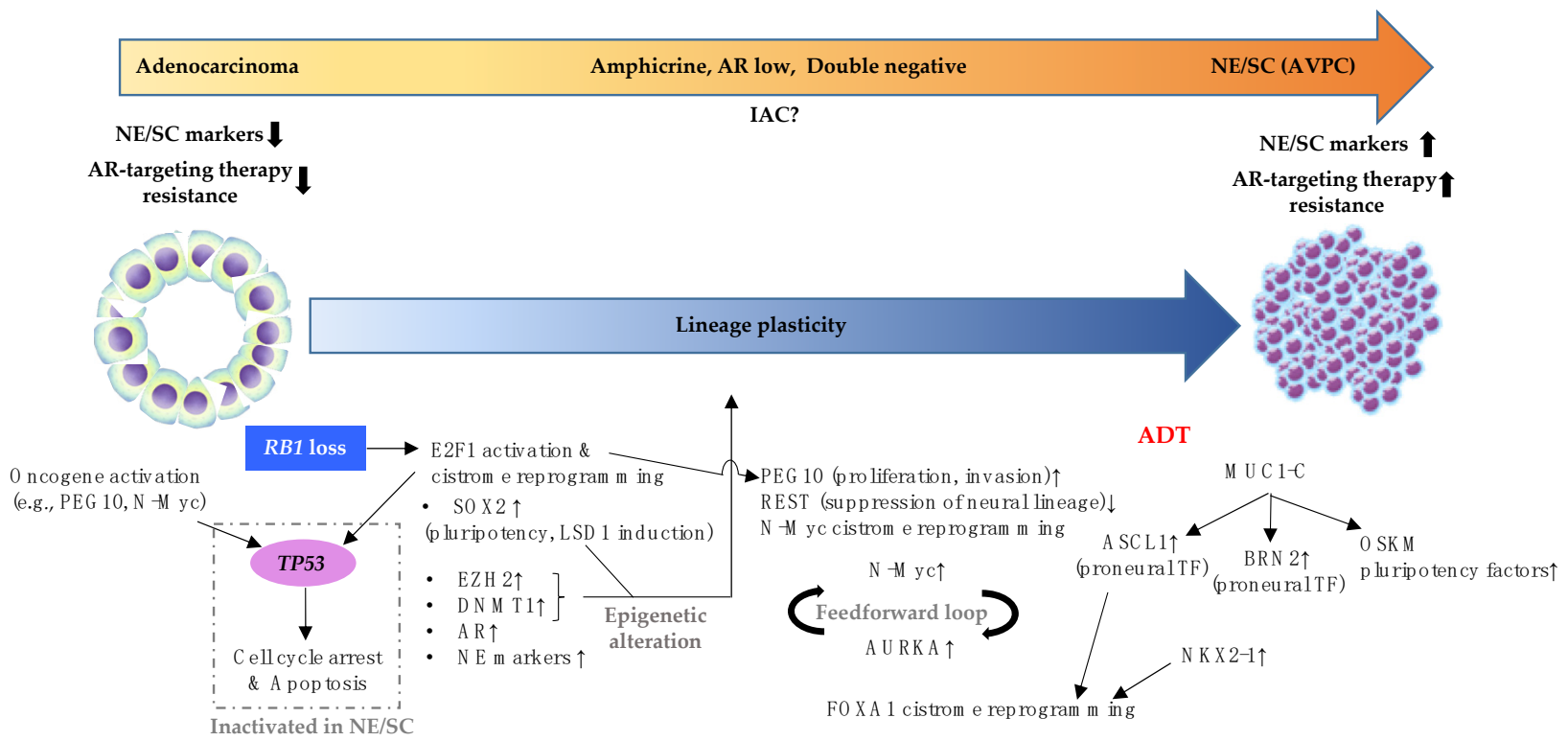

Figure 1. Schematic presentation of molecular events during NE/SC development. Abbreviations: IAC-intermediate atypical prostate cancer, AVPC - aggressive variant prostate cancer, OSKM-OCT4, SOX2, KLF4 and MYC. 


\subsection{Activation and Dysregulation of E2F1 Cistrome Caused by RB1 Loss}

In normal non-proliferating cells, hypophosphorylated RB inhibits the activity of E2Fs (including E2F1 upregulated in NE/SC [1]) through direct binding [31]. Upon mitogenic stimulation, the sequential hyperphosphorylation of RB by activated cyclin-dependent kinases results in the loss of RB function, followed by release of E2Fs from RB, promoting the expression of E2Fs target genes necessary for cell cycle progression and DNA synthesis [31]. In PCa, RB1 loss is rare in primary disease [32-34], but ADT may select for tumor loci with low RB1 activity to bypass cell-cycle blockage imposed by ADT [35].

Accordingly, in NE/SC where RB1 is often inactivated, E2F1 activity is elevated [1]. In general, E2Fs including E2F1 engage in cell-fate decision makings in many cell types, and their activation results in stem cell expansion, inhibition of differentiation and altered lineage choices upon differentiation [36]. In PCa, RB1 loss not only induces E2F1 binding to canonical E2F1 targets, but also reprograms E2F1 transcriptional activity by inducing E2F1 binding to non-canonical E2F1 targets [37].

\subsection{Consequences of Activated and Dysregulated E2F1 Cistrome}

Overactivation and dysregulation of E2F1 cistrome with expanded binding capacity contributes to NE/SC development by inducing the expression of several key transcription factors and epigenetic modifiers. The first example of dysregulated E2F1 cistrome is the reprogramming transcription factor SOX2 which is a known E2F1 target gene [38,39]. SOX2 is a critical factor to maintain pluripotency as well as a lineage specifier for neural lineage [40]. In PCa, SOX2 elevated by loss of TP53 and RB1 has been reported to drive lineage plasticity promoting NE/SC development [41]. This SOX2-driven lineage switching accompanies global hypomethylation of both histone $\mathrm{H} 3$ at lysine 4 and histone $\mathrm{H} 3$ at lysine 9, which may be mediated by LSD1 (lysine-specific demethylase 1) [42].

$\mathrm{NE} / \mathrm{SC}$ is known to possess epigenetic profiles including DNA methylation $[30,43]$ and histone modification [44] distinct from those of CRPC adenocarcinoma. A key player is EZH2 (enhancer of zeste homolog 2) whose expression is also elevated in NE/SC [1]. $\mathrm{EZH} 2$ is another direct downstream target of RB1-E2F pathway [45], and considered to be a master regulator of epigenetic rewiring in NE/SC [46].EZH2 is a catalytic subunit of the Polycomb repressive complex 2 (PRC2), and PRC2 epigenetically represses genes required for differentiation to maintain the pluripotent state [47]. In support of EZH2 as a master regulator in NE/SC, EZH2 inhibition has been shown to prevent NE/SC development in PCa cell lines [48]. Furthermore, Phase I clinical trial of EZH2 inhibitor (Tazemetostat) in combination with AR-targeted drugs against AVPC is currently underway (NCT04179864). In addition, the efficacy of Lirametostat (CPI-1205, a selective inhibitor of EZH2) in combination with enzalutamide or abiraterone is currently being evaluated in metastatic CRPC cohort (NCT03480646) [49], though its potential benefit to NE/SC patients has yet to be evaluated.

As another example of epigenetic regulators altered by TP53/RB1 loss, NE/SC expresses a higher level of methylation maintenance enzyme called DNMT1 (DNA methyltransferase 1) [30]. Here again, p53 and RB play a pivotal role in DNMT1 regulation by transcriptionally suppressing DNMT1 [50], which explains DNMT1 elevation in NE/SC that lost the function of TP53 and RB1. Moreover, EZH2 physically interacts with DNMTs by serving a recruitment platform and this interaction is required for $\mathrm{CpG}$ methylation of EZH2-target promoters [51], and trimethylation of H3K27 (histone H3 Lys27) carried out by EZH2 is necessary for de novo DNMTs-mediated DNA methylation [52]. These findings highlight the intricate interplay among these epigenetic modifiers downstream of RB1-E2F pathway.

Elevated E2F1 activity by RB1 loss also leads to AR upregulation as E2F1 is recruited to the AR regulatory locus and induces AR expression [32]. Although AR transcriptional activity is low in fully grown NE/SC [1], a substantial fraction (35\%) of CRPC with combined biallelic loss of RB1 and TP53 was classified as AR-positive adenocarcinomas without neuroendocrine features [53]. Thus, E2F1-mediated AR elevation may drive progression 
of prostate tumors with AR dependency prior to eventual loss of this dependency during NE/SC development. Further supporting the significant impacts of RB1 loss and the resultant E2F1 cistrome dysregulation, E2F1 has been reported to bind to promoter regions of NE markers such as CGA, SYP and NSE upon RB1 knockdown [54].

A recent study focused on E2F1 as a therapeutic target of NE/SC. Since E2F1 itself is not currently directly targetable, BRD4 that cooperates with E2F1 to activate NE/SC lineage plasticity program has been targeted with BET bromodomain inhibitors (BETi) [55]. BETi showed therapeutic effects not only in preclinical models, but also in some NE/SC patients treated with BETi ZEN-3694 (NCT02711956) [55], highlighting the importance of E2F1 in NE/SC development. Taken together, several critical regulators downstream of E2F1 orchestrate NE/SC development.

\subsection{The Role of TP53 Loss in NE/SC Development}

What is the role of TP53 inactivation during NE/SC development? It is well established that TP53 mutations, often associated with loss of function, are more frequently detected in CRPC (prior to NE/SC) than RB1 loss [33]. In a preclinical mouse model, inactivation of $R b$ alone only led to PIN (prostatic intraepithelial neoplasia) formation and concurrent deletion of Tp53 was required for the development of metastatic carcinoma with neuroendocrine features [56], suggesting TP53 loss may be a prerequisite for functions mediated by RB1 loss. This can be explained by the function of TP53 as a cellular gatekeeper, in which stress signals including loss of tumor suppressors induce several downstream events such as cell cycle arrest and apoptosis, and not surprisingly, RB1 loss is one of these TP53 activating events [57]. More specifically, E2F1 accumulation caused by $R B 1$ loss subsequently activates the ARF/Mdm2/p53 pathway, leading to induction of apoptosis [58]. Therefore, TP53 inactivation may be required for CRPC cells to fully exploit the aforementioned benefits of dysregulated E2F1 cistrome during the development of NE/SC signified by RB1 loss.

In addition to RB1 loss, oncogene activation is also a TP53 inducer [57]. In the context of NE/SC, for instance, when oncogenic PEG10 (another E2F1 target gene that promotes invasion and proliferation of NE/SC; to be detailed in the next section) is overexpressed in LNCaP harboring WT TP53, TP53 expression is induced and growth promotion does not occur, whereas cell growth increase once TP53 is knocked down [59]. Another example of TP53-promoting oncogene is MYCN (also to be detailed in the next section). MYCN amplification has been reported to activate TP53 and induce subsequent apoptosis in neuroblastoma [60]. Therefore, in NE/SC in which MYCN expression is often elevated [61], loss of TP53 may be required for MYCN to fully exert its oncogenic effects.

To summarize, although TP53/RB1 loss is not unique to NE/SC, current data support the nomination of TP53/RB1 loss as the common genomic denominator necessary for NE/SC development.

\section{Additional Alterations Required for NE/SC Development Are Often Associated with ADT}

Although it seems almost unquestionable that loss of TP53 and RB1 is necessary for NE/SC, next-generation sequencing data of matched DNA and RNA show that a substantial fraction (35\%) of CRPC with combined biallelic loss of TP53 and RB1 was classified as AR-positive adenocarcinomas without neuroendocrine features [53]. Furthermore, double knockout of TP53 and RB1 in LNCaP PCa cell lines did not induce the expression of NEassociated genes [53]. Therefore, additional genetic or epigenetic alterations that potentially tilt the cell fate towards full-fledged NE/SC may be required.

LTL331 PDX (patient-derived xenograft) is an elegant model that demonstrates a transition from adenocarcinoma (LTL331) to NE/SC (LTL331R). Interestingly, adenocarcinoma LTL331 already harbors heterozygous copy loss at the RB1 and TP53 gene loci, and the hemizygous loss-of-function mutations in the remaining alleles, meaning that both genes are already severely compromised. Yet, LTL331 does not transform to NE/SC until castration of the host, suggesting that castration (aka ADT) plays an important role in 
NE/SC development in this model [59], which is also consistent with clinical observations that longer duration of ADT increases NE/SC incidence [62]. The LTL331 model has been used to define key molecular events as a consequence of ADT that drives the transition from adenocarcinoma to NE/SC. For example, PEG10 (Paternally Expressed 10, one of E2F1 target genes) was identified as a key molecule. In LTL331, AR inhibits the expression of PEG10 by a direct binding to PEG10 promoter, whereas castration results in elevated PEG10 expression, promoting invasion and proliferation of NE/SC [59].

Another important molecule, REST (RE1-silencing transcription factor), is also under the control of AR. REST suppresses the expression of neuronal genes in non-neuronrelated tissues. Regarding REST regulation by AR, AR inhibits REST degradation by inhibiting a REST ubiquitin ligase [63]. Thus, following castration, REST expression is downregulated, and loss of REST in turn triggers the expression of neuron-specific genes during NE/SC development [64]. Although other study suggested that REST loss only induces the expression of a limited set of NE/SC-associated genes and is not sufficient to fully transform CRPC to NE/SC [65], it is highly likely that REST loss plays a part in NE/SC development.

N-Myc (encoded by $M Y C N$ ), a well-known oncogenic transcription factor, is significantly elevated in NE/SC [61], and is capable of transforming human prostate epithelial cells to NE/SC in vitro [66]. Notably, ADT reprograms N-Myc cistrome in the direction towards neural lineage. In the presence of androgen, N-Myc binds to regulatory sequences associated with AR binding upstream of AR target genes. Upon androgen withdrawal, $\mathrm{N}-\mathrm{Myc}$ is redirected towards promoters of neural-lineage genes leading to transcriptional activation of these genes [67]. Additionally, E2F1 cistome reprogramming discussed in the previous section may be involved in this N-Myc activity augmentation. Myc target is one of pathways enriched upon RB1 loss, implicating dysregulated E2F1 cistrome in $\mathrm{N}-\mathrm{Myc}$ upregulation [37]. Although direct activation of N-Myc by E2F1 is yet to be demonstrated in PCa and further studies are needed, E2Fs have been reported to promote N-Myc expression by binding to $M Y C N$ promoter in other cancer types [68], raising the possibility that N-Myc elevation, triggered by dysregulated E2F1 cistrome, may contribute to NE/SC development.

N-Myc activity is also intricately associated with AURKA (Aurora kinase A) in NE/SC. AURKA and N-Myc are concurrently overexpressed in NE/SC [61]. Overexpression of AURKA results in aneuploidy and tumorigenesis [69]. In NE/SC, AURKA exerts its oncogenic effects through a feedforward loop with N-Myc. N-Myc enhances the expression of AURKA and AURKA increases N-Myc stability by inhibiting N-Myc-targeting ubiquitin ligase [70]. AURKA inhibition appears to be effective against a certain subset of N-Myc/AURKA-high NE/SC [66]. Interestingly, AR enhances the expression of AURKA [71], giving rise to a question regarding how AURKA is upregulated in AR-indifferent NE/SC. The feedforward interaction between AURKA and N-Myc suggests that N-Myc can drive AURKA expression independent of AR in NE/SC.

ADT also induces the expression of proneural transcription factor ASCL1 (AchaeteScute Complex-Like 1) [72] and BRN2 (encoded by POU3F2) [73]. ASCL1 and BRN2 promote neurogenesis and are two of three transcription factors that are required to convert non-neural somatic cells into neurons [74]. ASCL1 together with NKX2-1 (also elevated by castration in LTL331 model) have been reported to induce reprogramming of FOXA1 cistrome [75]. Specifically, in adenocarcinoma, FOXA1 binds to regulatory elements of prostate-lineage genes such as KLK3, HOXB13, and NKX3-1. FOXA1 dramatically changes its cistrome in NE/SC and binds to regulatory elements of NE/SC-associated genes. This FOXA1 cistrome reprogramming was reproduced by ectopic expression of ASCL1 and NKX2-1 [75]. BRN2 is highly expressed in NE/SC, and is directly repressed by AR which binds to the androgen response element (ARE) of BRN2 [73]. BRN2 induces the expression of NE markers and confers aggressive phenotypes to NE/SC [73].

A recent study has shed light on the pleiotropic functions of MUC1-C (an oncogenic C-terminal transmembrane subunit of Mucin1) in this intricate interplay among afore- 
mentioned proneural and pluripotent transcription factors. As opposed to AR which represses BRN2 expression, MUC1-C activates BRN2 expression by directly binding to BRN2 promoter in collaboration with MYC. Furthermore, silencing MUC1-C decreases expression of ASCL1 and the four OSKM pluripotency factors (OCT4, SOX2, KLF4 and MYC) [76]. In line with the importance of AR suppression in NED, AR suppresses MUC1-C transcription by directly binding to ARE in MUC1-C promoter region [77].

Collectively, the findings summarized above support the general concept that while dual inactivation of TP53 and RB1 is the foundation of NE/SC development, molecular events triggered by ADT are required for the completion of NE/SC development. The transition from adenocarcinoma to NE/SC therefore may involve NE/SC-associated key transcription factors and cistrome reprogramming that further tilt the cell fate towards neuroendocrine lineage.

\section{Histological Classification of PCa Disease Continuum from Adenocarcinoma to NE/SC and Associated Molecular Events}

In general, the transition from adenocarcinoma to NE/SC can be explained by molecular events occurring under the selective pressure of potent AR-targeting agents in the context of TP53/RB1 loss. However, the transition process should be considered a temporally and spatially complex process of tumor evolution. There, histological and molecular variants during NE/SC development should be expected. Recently, Labrecque et al. proposed classifying disease continuum between CRPC adenocarcinoma and NE/SC into the following five categories: ARPC (adenocarcinomas with AR and PSA), AR-low PCa (weak AR and PSA, and negative for NE markers), amphicrine PCa (coexpress AR, PSA, and NE markers), double-negative PCa (DNPC, negative for AR, PSA, and NE markers) and NE/SC [65].

Given the spatial and temporal heterogeneity of the disease, it is challenging to precisely delineate temporal molecular events described in the previous sections during transition from adenocarcinoma to NE/SC. However, the LTL331 model which accurately recapitulates the clinical course of a patient from whom LTL331 was derived gives us some clues regarding the key molecule drivers. Table 4 summarizes the gene expression changes of molecules discussed in this review during NE/SC development in LTL331 model [59]. It takes 6-8 months for LTL331 (adenocarcinoma) to become LTL331R (NE/SC) after castration, and although the term "double-negative" was not used in this Akamatsu et al.'s paper, their IHC data showed that LTL331 becomes negative for AR, PSA and chromogranin A at post-castration 2-3-month timepoint, which recapitulates DNPC [59]. Therefore, one can surmise that in the context of TP53/RB1 loss (in LTL331), several additional molecular events that depend on AR suppression evolve to drive the development of NE/SC. Histological and molecular intermediates in the process of this transition have been evaluated more carefully in this model. With regards to histological intermediate phases between adenocarcinoma and NE/SC, a set of genes associated with squamous cancers was elevated in a subset of AR-low PCa and DNPC, implying the existence of a transition state to squamous CRPC. However, a determinant to switch cell fate to squamous lineage is yet to be determined [65]. Bluemn et al. particularly investigated DNPC, and found elevated FGF and MAPK signaling pathway in DNPC, enabling bypass of AR dependence [78]. In addition, DNPC has been shown to acquire mesenchymal and stem-like traits through the activation of PRC1 (Polycomb Repressor Complex 1), and PRC1 promotes metastasis of DNPC [79].

Last but not least, the West Coast SU2C-PCF Dream Team recently proposed a morphologically distinct subtype of PCa called intermediate atypical prostate cancer (IAC) that shows features of both adenocarcinoma and NE/SC (NCT02432001) [80]. IAC showed a gene expression signature that is intermediate to adenocarcinoma and NE/SC [80]. How IAC is related to the other categories of CRPC proposed in Labrecque et al. (ARPC, AR-low PCa, amphicrine PCa and DNPC [65]) remains to be determined. 
Table 4. Relative expression of key molecules during NED based on RNA sequencing data of the LTL331 model. Extracted from Akamatsu et al. Supplementary Table S2 [59]. Normalized mRNA read counts were deivided by read counts at pre Cx1.

\begin{tabular}{|c|c|c|c|c|c|c|}
\hline \multirow[b]{2}{*}{ Gene Name } & \multicolumn{2}{|c|}{ Adenocarcinoma } & \multicolumn{2}{|c|}{ Double negative } & \multirow[b]{2}{*}{$\begin{array}{c}\text { LTL331 NE/SC } \\
1\end{array}$} & \multirow{2}{*}{$\begin{array}{c}\text { NE/SC } \\
\begin{array}{c}\text { LTL331 NE/SC } \\
2\end{array}\end{array}$} \\
\hline & LTL331 Pre Cx1 & LTL331 Pre Cx2 & $\begin{array}{c}\text { LTL331 Post Cx } \\
8 \mathrm{wk}\end{array}$ & $\begin{array}{c}\text { LTL331 Post Cx } \\
\text { 12wk }\end{array}$ & & \\
\hline ASCL1 & 1.00 & 0.55 & 0.33 & 3.82 & 2.52 & 1.52 \\
\hline AURKA & 1.00 & 1.06 & 0.43 & 0.26 & 1.75 & 2.20 \\
\hline DNMT1 & 1.00 & 1.43 & 1.43 & 1.19 & 2.95 & 2.93 \\
\hline E2F1 & 1.00 & 0.94 & 0.63 & 0.36 & 3.37 & 3.79 \\
\hline FOXA1 & 1.00 & 1.11 & 0.96 & 0.81 & 0.12 & 0.13 \\
\hline MUC1 & 1.00 & 0.39 & 0.24 & 0.33 & 2.18 & 1.14 \\
\hline$M Y C N$ & 1.00 & 1.16 & 2.27 & 2.34 & 6.82 & 6.84 \\
\hline NKX2-1 & 1.00 & 5.17 & 17.71 & 11.02 & 5.13 & 13.95 \\
\hline PEG10 & 1.00 & 7.31 & 18.68 & 19.82 & 370.77 & 702.05 \\
\hline $\begin{array}{l}\text { POU3F2 } \\
\text { (BRN2) }\end{array}$ & 1.00 & 0.54 & 0.70 & 1.45 & 146.84 & 210.52 \\
\hline REST & 1.00 & 1.28 & 1.57 & 1.76 & 0.02 & 0.01 \\
\hline SOX2 & 1.00 & 2.87 & 1.22 & 12.25 & 6350.99 & 4626.95 \\
\hline
\end{tabular}

Abbreviations: Cx-Castration.

\section{Early Detection of NE/SC}

How can we harness the molecular understanding of NE/SC and make use of the key molecular drivers for early detection of NE/SC? Several lines of evidence show that aberrations in TP53, RB1 and PTEN are associated with poor clinical outcomes. For example, deleterious variants of TP53 and RB1 were associated with poorer outcomes both in localized and metastatic diseases [34]. PCa with gene expression profile associated with TP53/RB1 loss showed worse overall survival (OS) and poor treatment response to AR-targeted therapies [53]. Not surprisingly, these aberrations in RB1, TP53 and PTEN in aggressive diseases overlap with molecular features of clinically defined AVPC [28]. In other words, detection of these aberrations early may help to predict the emergence of NE/SC. Although frequency is lower in comparison with advanced diseases, TP53, RB1 and PTEN alterations can be readily detected in primary localized prostate cancer $[33,34]$, and alterations in TP53, RB1 and PTEN are associated with increased risk of relapse in localized disease [34]. Other biomarkers that predict the emergence of NE/SC at the treatment-naïve stage are AURKA and MYCN amplifications [81]. It has been reported that a large proportion of patients who develop NE/SC at later stages of the disease already carry concurrent $A U R K A$ and $M Y C N$ amplifications in their primary PCa in comparison with a random and unselected PCa cohort [81]. Thus, when those alterations are detected in primary $\mathrm{PCa}$, patients should be closely monitored, and intensive therapeutic intervention and a possibility of NE/SC emergence should be considered.

Early detection of NE/SC may be particularly relevant in the setting of systemic therapies. In this setting, it is often not feasible to acquire tissue biopsies. Cell-free DNA (cfDNA) testing can be a feasible option during generally long-term PCa follow-up periods. McNair et al. has shown that copy number alterations in RB1 and RB pathway genes can be readily traced by cfDNA testing [37]. Given the contribution of RB1 loss and consequent E2F1 cistrome dysregulation to NE/SC development as described in the previous section, this point-of-care RB testing may lead to clinical benefit [37]. To further explore the potential of cfDNA testing in NE/SC early diagnosis, Beltran et al. employed the combined panels of $\mathrm{NE}$ /SC-associated genomic and epigenomic alterations to identify NE/SC patients [82]. In their study, there was a patient whose cfDNA profile showed NE/SC characteristics prior 
to actual clinical manifestations of NE/SC liver metastasis, suggesting that cfDNA testing is useful to capture NE/SC-related molecular events earlier than clinical manifestations [82].

Finally, little has been done from NE/SC prevention perspective. As androgen withdrawal plays a pivotal role in NE/SC development $[59,62]$, androgen supplementation may delay the onset of NE/SC. Bipolar androgen therapy (BAT) recently came under the spotlight and is showing promising results so far in terms of re-sensitization to enzalutamide [83]. It would be informative to identify patients at high risk for NE/SC (e.g., those carrying TP53, RB1 and PTEN alteration or AURKA/MYCN amplification in their primary PCa or biopsies at later stages) and compare the long-term prevalence of NE/SC in BAT-treated patients versus untreated patients.

Together, it is possible to predict the emergence of NE/SC to a certain extent based on primary PCa tissue specimens as well as liquid biopsies. Further development in these areas will be necessary to drive efforts in early detection of NE/SC and facilitate development of rationalized treatment strategies.

\section{Conclusions}

In this review, we summarized clinical and pathological characteristics of NE/SC and reviewed molecular events underlying transition from adenocarcinoma to NE/SC with a special focus on key drivers including inactivation of TP53/RB1 and other drivers emerging upon androgen withdrawal. Some molecular definitions may be readily utilized in the clinical settings to complement existing pathological and clinical definitions. Although tissue- and liquid-biopsy based testing for the purpose of predicting NE/SC is still at the exploratory stage, it is a promising area of research and development that will enable early detection and precision therapy for a lethal form of prostate cancer trending to rise in frequency due to early use of potent AR-targeting agents.

Author Contributions: Conceptualization, M.K. and J.L.; writing—original draft preparation, M.K.; writing-review and editing, J.L.; project administration, J.L.; funding acquisition, J.L. All authors have read and agreed to the published version of the manuscript.

Funding: Relevant research activities are partially funded by W81XWH-19-1-0686 (to J.L.)

Institutional Review Board Statement: Not applicable.

Informed Consent Statement: Not applicable.

Data Availability Statement: Not applicable.

Conflicts of Interest: J.L. has served as a paid consultant/advisor for Sun Pharma, Janssen, Tolero. J.L. has received research funding to his institution from Orion, Astellas, Sanofi, Constellation, Calibr, Pandomedx, Cardiff Oncology, and Gilead, and is a co-inventor of a technology owned by Johns Hopkins University and licensed to Tokai, Qiagen, and A\&G.

\section{References}

1. Aggarwal, R.; Huang, J.; Alumkal, J.J.; Zhang, L.; Feng, F.Y.; Thomas, G.V.; Weinstein, A.S.; Friedl, V.; Zhang, C.; Witte, O.N.; et al. Clinical and Genomic Characterization of Treatment-Emergent Small-Cell Neuroendocrine Prostate Cancer: A Multi-institutional Prospective Study. J. Clin. Oncol. 2018, 36, 2492-2503. [CrossRef]

2. Davies, A.H.; Beltran, H.; Zoubeidi, A. Cellular plasticity and the neuroendocrine phenotype in prostate cancer. Nat. Rev. Urol. 2018, 15, 271-286. [CrossRef] [PubMed]

3. Epstein, J.I.; Amin, M.B.; Beltran, H.; Lotan, T.L.; Mosquera, J.M.; Reuter, V.E.; Robinson, B.D.; Troncoso, P.; Rubin, M.A. Proposed morphologic classification of prostate cancer with neuroendocrine differentiation. Am. J. Surg. Pathol. 2014, $38,756-767$. [CrossRef]

4. Aparicio, A.M.; Harzstark, A.L.; Corn, P.G.; Wen, S.; Araujo, J.C.; Tu, S.M.; Pagliaro, L.C.; Kim, J.; Millikan, R.E.; Ryan, C.; et al. Platinum-based chemotherapy for variant castrate-resistant prostate cancer. Clin. Cancer. Res. 2013, 19, 3621-3630. [CrossRef]

5. Vlachostergios, P.J.; Puca, L.; Beltran, H. Emerging Variants of Castration-Resistant Prostate Cancer. Curr. Oncol. Rep. 2017, 19, 32. [CrossRef] [PubMed]

6. Humphrey, P.A.; Moch, H.; Cubilla, A.L.; Ulbright, T.M.; Reuter, V.E. The 2016 WHO Classification of Tumours of the Urinary System and Male Genital Organs-Part B: Prostate and Bladder Tumours. Eur. Urol. 2016, 70, 106-119. [CrossRef] 
7. Kaur, H.; Samarska, I.; Lu, J.; Faisal, F.; Maughan, B.L.; Murali, S.; Asrani, K.; Alshalalfa, M.; Antonarakis, E.S.; Epstein, J.I.; et al. Neuroendocrine differentiation in usual-type prostatic adenocarcinoma: Molecular characterization and clinical significance. Prostate 2020, 80, 1012-1023. [CrossRef]

8. Tamas, E.F.; Epstein, J.I. Prognostic significance of paneth cell-like neuroendocrine differentiation in adenocarcinoma of the prostate. Am. J. Surg. Pathol. 2006, 30, 980-985. [CrossRef]

9. Yao, J.L.; Madeb, R.; Bourne, P.; Lei, J.; Yang, X.; Tickoo, S.; Liu, Z.; Tan, D.; Cheng, L.; Hatem, F.; et al. Small cell carcinoma of the prostate: An immunohistochemical study. Am. J. Surg. Pathol. 2006, 30, 705-712. [CrossRef] [PubMed]

10. Wang, W.; Epstein, J.I. Small cell carcinoma of the prostate. A morphologic and immunohistochemical study of 95 cases. Am. J. Surg. Pathol. 2008, 32, 65-71. [CrossRef]

11. Evans, A.J.; Humphrey, P.A.; Belani, J.; van der Kwast, T.H.; Srigley, J.R. Large cell neuroendocrine carcinoma of prostate: A clinicopathologic summary of 7 cases of a rare manifestation of advanced prostate cancer. Am. J. Surg. Pathol. 2006, 30, 684-693. [CrossRef]

12. Bonk, S.; Kluth, M.; Hube-Magg, C.; Polonski, A.; Soekeland, G.; Makropidi-Fraune, G.; Moller-Koop, C.; Witt, M.; Luebke, A.M.; Hinsch, A.; et al. Prognostic and diagnostic role of PSA immunohistochemistry: A tissue microarray study on 21,000 normal and cancerous tissues. Oncotarget 2019, 10, 5439-5453. [CrossRef]

13. Gupta, S.; Vanderbilt, C.; Abida, W.; Fine, S.W.; Tickoo, S.K.; Al-Ahmadie, H.A.; Chen, Y.B.; Sirintrapun, S.J.; Chadalavada, K.; Nanjangud, G.J.; et al. Immunohistochemistry-based assessment of androgen receptor status and the AR-null phenotype in metastatic castrate resistant prostate cancer. Prostate Cancer Prostatic Dis. 2020, 23, 507-516. [CrossRef]

14. Gurel, B.; Ali, T.Z.; Montgomery, E.A.; Begum, S.; Hicks, J.; Goggins, M.; Eberhart, C.G.; Clark, D.P.; Bieberich, C.J.; Epstein, J.I. NKX3. 1 as a marker of prostatic origin in metastatic tumors. Am. J. Surg. Pathol. 2010, 34, 1097. [CrossRef] [PubMed]

15. Kristiansen, I.; Stephan, C.; Jung, K.; Dietel, M.; Rieger, A.; Tolkach, Y.; Kristiansen, G. Sensitivity of HOXB13 as a diagnostic immunohistochemical marker of prostatic origin in prostate cancer metastases: Comparison to PSA, prostein, androgen receptor, ERG, NKX3. 1, PSAP, and PSMA. Int. J. Mol. Sci. 2017, 18, 1151. [CrossRef] [PubMed]

16. Tsai, H.; Morais, C.L.; Alshalalfa, M.; Tan, H.-L.; Haddad, Z.; Hicks, J.; Gupta, N.; Epstein, J.I.; Netto, G.J.; Isaacs, W.B. Cyclin D1 loss distinguishes prostatic small-cell carcinoma from most prostatic adenocarcinomas. Clin. Cancer Res. 2015, 21, 5619-5629. [CrossRef]

17. Cheng, S.; Prieto-Dominguez, N.; Yang, S.; Connelly, Z.M.; StPierre, S.; Rushing, B.; Watkins, A.; Shi, L.; Lakey, M.; Baiamonte, L.B. The expression of YAP1 is increased in high-grade prostatic adenocarcinoma but is reduced in neuroendocrine prostate cancer. Prostate Cancer Prostatic Dis. 2020, 23, 661-669. [CrossRef]

18. Helle, K.B.; Corti, A.; Metz-Boutigue, M.H.; Tota, B. The endocrine role for chromogranin A: A prohormone for peptides with regulatory properties. Cell Mol. Life Sci. 2007, 64, 2863-2886. [CrossRef]

19. Ferrero-Pous, M.; Hersant, A.M.; Pecking, A.; Bresard-Leroy, M.; Pichon, M.F. Serum chromogranin-A in advanced prostate cancer. BJU Int. 2001, 88, 790-796. [CrossRef]

20. Wiedenmann, B.; Franke, W.W.; Kuhn, C.; Moll, R.; Gould, V.E. Synaptophysin: A marker protein for neuroendocrine cells and neoplasms. Proc. Natl. Acad. Sci. USA 1986, 83, 3500-3504. [CrossRef] [PubMed]

21. Bösmüller, H.-C.; Wagner, P.; Pham, D.L.; Fischer, A.K.; Greif, K.; Beschorner, C.; Sipos, B.; Fend, F.; Staebler, A. CD56 (neural cell adhesion molecule) expression in ovarian carcinomas: Association with high-grade and advanced stage but not with neuroendocrine differentiation. Int. J. Gynecol. Cancer 2017, 27, 239-245. [CrossRef]

22. Agoff, S.N.; Lamps, L.W.; Philip, A.T.; Amin, M.B.; Schmidt, R.A.; True, L.D.; Folpe, A.L. Thyroid transcription factor-1 is expressed in extrapulmonary small cell carcinomas but not in other extrapulmonary neuroendocrine tumors. Mod. Pathol. 2000, 13, 238-242. [CrossRef] [PubMed]

23. Park, J.W.; Lee, J.K.; Witte, O.N.; Huang, J. FOXA2 is a sensitive and specific marker for small cell neuroendocrine carcinoma of the prostate. Mod. Pathol. 2017, 30, 1262. [CrossRef]

24. Xin, Z.; Zhang, Y.; Jiang, Z.; Zhao, L.; Fan, L.; Wang, Y.; Xie, S.; Shangguan, X.; Zhu, Y.; Pan, J. Insulinoma-associated protein 1 is a novel sensitive and specific marker for small cell carcinoma of the prostate. Hum. Pathol. 2018, 79, 151-159. [CrossRef]

25. Fujino, K.; Yasufuku, K.; Kudoh, S.; Motooka, Y.; Sato, Y.; Wakimoto, J.; Kubota, I.; Suzuki, M.; Ito, T. INSM1 is the best marker for the diagnosis of neuroendocrine tumors: Comparison with CGA, SYP and CD56. Int. J. Clin. Exp. Pathol. 2017, 10, $5393-5405$.

26. Conteduca, V.; Oromendia, C.; Eng, K.W.; Bareja, R.; Sigouros, M.; Molina, A.; Faltas, B.M.; Sboner, A.; Mosquera, J.M.; Elemento, O.; et al. Clinical features of neuroendocrine prostate cancer. Eur. J. Cancer 2019, 121, 7-18. [CrossRef] [PubMed]

27. Tetu, B.; Ro, J.Y.; Ayala, A.G.; Johnson, D.E.; Logothetis, C.J.; Ordonez, N.G. Small cell carcinoma of the prostate. Part I. A clinicopathologic study of 20 cases. Cancer 1987, 59, 1803-1809. [CrossRef]

28. Aparicio, A.M.; Shen, L.; Tapia, E.L.; Lu, J.F.; Chen, H.C.; Zhang, J.; Wu, G.; Wang, X.; Troncoso, P.; Corn, P.; et al. Combined Tumor Suppressor Defects Characterize Clinically Defined Aggressive Variant Prostate Cancers. Clin. Cancer Res. 2016, 22, 1520-1530. [CrossRef]

29. Brown, L.C.; Halabi, S.; Humeniuk, M.S.; Wu, Y.; Oyekunle, T.; Huang, J.; Anand, M.; Davies, C.; Zhang, T.; Harrison, M.R. Efficacy of the PD-L1 inhibitor avelumab in neuroendocrine or aggressive variant prostate cancer: Results from a phase II, single-arm study. J. Clin. Oncol. 2021, 39, 89. [CrossRef] 
30. Beltran, H.; Prandi, D.; Mosquera, J.M.; Benelli, M.; Puca, L.; Cyrta, J.; Marotz, C.; Giannopoulou, E.; Chakravarthi, B.V.; Varambally, S.; et al. Divergent clonal evolution of castration-resistant neuroendocrine prostate cancer. Nat. Med. 2016, 22, 298-305. [CrossRef]

31. Chen, H.Z.; Tsai, S.Y.; Leone, G. Emerging roles of E2Fs in cancer: An exit from cell cycle control. Nat. Rev. Cancer 2009, 9, 785-797. [CrossRef]

32. Sharma, A.; Yeow, W.S.; Ertel, A.; Coleman, I.; Clegg, N.; Thangavel, C.; Morrissey, C.; Zhang, X.; Comstock, C.E.; Witkiewicz, A.K.; et al. The retinoblastoma tumor suppressor controls androgen signaling and human prostate cancer progression. J. Clin. Investig. 2010, 120, 4478-4492. [CrossRef]

33. Abeshouse, A.; Ahn, J.; Akbani, R.; Ally, A.; Amin, S.; Andry, C.D.; Annala, M.; Aprikian, A.; Armenia, J.; Arora, A. The molecular taxonomy of primary prostate cancer. Cell 2015, 163, 1011-1025. [CrossRef]

34. Hamid, A.A.; Gray, K.P.; Shaw, G.; MacConaill, L.E.; Evan, C.; Bernard, B.; Loda, M.; Corcoran, N.M.; Van Allen, E.M.; Choudhury, A.D.; et al. Compound Genomic Alterations of TP53, PTEN, and RB1 Tumor Suppressors in Localized and Metastatic Prostate Cancer. Eur. Urol. 2019, 76, 89-97. [CrossRef]

35. Sowalsky, A.G.; Ye, H.; Bhasin, M.; Van Allen, E.M.; Loda, M.; Lis, R.T.; Montaser-Kouhsari, L.; Calagua, C.; Ma, F.; Russo, J.W.; et al Neoadjuvant-Intensive Androgen Deprivation Therapy Selects for Prostate Tumor Foci with Diverse Subclonal Oncogenic Alterations. Cancer Res. 2018, 78, 4716-4730. [CrossRef] [PubMed]

36. Julian, L.M.; Blais, A. Transcriptional control of stem cell fate by E2Fs and pocket proteins. Front Genet. 2015, 6, 161. [CrossRef] [PubMed]

37. McNair, C.; Xu, K.; Mandigo, A.C.; Benelli, M.; Leiby, B.; Rodrigues, D.; Lindberg, J.; Gronberg, H.; Crespo, M.; De Laere, B.; et al. Differential impact of RB status on E2F1 reprogramming in human cancer. J. Clin. Investig. 2018, 128, 341-358. [CrossRef] [PubMed]

38. Schaal, C.M.; Bora-Singhal, N.; Kumar, D.M.; Chellappan, S.P. Regulation of Sox2 and stemness by nicotine and electroniccigarettes in non-small cell lung cancer. Mol. Cancer 2018, 17, 149. [CrossRef]

39. Kareta, M.S.; Gorges, L.L.; Hafeez, S.; Benayoun, B.A.; Marro, S.; Zmoos, A.F.; Cecchini, M.J.; Spacek, D.; Batista, L.F.; $\mathrm{O}^{\prime}$ Brien, M.; et al. Inhibition of pluripotency networks by the $\mathrm{Rb}$ tumor suppressor restricts reprogramming and tumorigenesis. Cell Stem. Cell 2015, 16, 39-50. [CrossRef] [PubMed]

40. Zhang, S.; Cui, W. Sox2, a key factor in the regulation of pluripotency and neural differentiation. World J. Stem. Cells 2014, 6, 305-311. [CrossRef]

41. Mu, P.; Zhang, Z.; Benelli, M.; Karthaus, W.R.; Hoover, E.; Chen, C.-C.; Wongvipat, J.; Ku, S.-Y.; Gao, D.; Cao, Z. SOX2 promotes lineage plasticity and antiandrogen resistance in TP53-and RB1-deficient prostate cancer. Science 2017, 355, 84-88. [CrossRef]

42. Li, H.; Wang, L.; Li, Z.; Geng, X.; Li, M.; Tang, Q.; Wu, C.; Lu, Z. SOX2 has dual functions as a regulator in the progression of neuroendocrine prostate cancer. Lab. Investig. 2020, 100, 570-582. [CrossRef] [PubMed]

43. Zhao, S.G.; Chen, W.S.; Li, H.; Foye, A.; Zhang, M.; Sjostrom, M.; Aggarwal, R.; Playdle, D.; Liao, A.; Alumkal, J.J.; et al. The DNA methylation landscape of advanced prostate cancer. Nat. Genet. 2020, 52, 778-789. [CrossRef] [PubMed]

44. Clermont, P.L.; Lin, D.; Crea, F.; Wu, R.; Xue, H.; Wang, Y.; Thu, K.L.; Lam, W.L.; Collins, C.C.; Wang, Y.; et al. Polycomb-mediated silencing in neuroendocrine prostate cancer. Clin. Epigenetics 2015, 7, 40. [CrossRef]

45. Bracken, A.P.; Pasini, D.; Capra, M.; Prosperini, E.; Colli, E.; Helin, K. EZH2 is downstream of the pRB-E2F pathway, essential for proliferation and amplified in cancer. EMBO J. 2003, 22, 5323-5335. [CrossRef]

46. Davies, A.; Zoubeidi, A.; Selth, L.A. The epigenetic and transcriptional landscape of neuroendocrine prostate cancer. Endocr. Relat. Cancer 2020, 27, R35-R50. [CrossRef]

47. Lee, T.I.; Jenner, R.G.; Boyer, L.A.; Guenther, M.G.; Levine, S.S.; Kumar, R.M.; Chevalier, B.; Johnstone, S.E.; Cole, M.F.; Isono, K.; et al. Control of developmental regulators by Polycomb in human embryonic stem cells. Cell 2006, 125, 301-313. [CrossRef]

48. Zhang, Y.; Zheng, D.; Zhou, T.; Song, H.; Hulsurkar, M.; Su, N.; Liu, Y.; Wang, Z.; Shao, L.; Ittmann, M. Androgen deprivation promotes neuroendocrine differentiation and angiogenesis through CREB-EZH2-TSP1 pathway in prostate cancers. Nat. Commun. 2018, 9, 1-17. [CrossRef]

49. Taplin, M.-E.; Hussain, A.; Shore, N.D.; Bradley, B.; Trojer, P.; Lebedinsky, C.; Senderowicz, A.M.; Antonarakis, E.S. A phase 1b/2 study of CPI-1205, a small molecule inhibitor of EZH2, combined with enzalutamide (E) or abiraterone/prednisone (A/P) in patients with metastatic castration resistant prostate cancer (mCRPC). J. Clin. Oncol. 2018, 36, 6. [CrossRef]

50. Lin, R.K.; Wang, Y.C. Dysregulated transcriptional and post-translational control of DNA methyltransferases in cancer. Cell Biosci. 2014, 4, 46. [CrossRef] [PubMed]

51. Vire, E.; Brenner, C.; Deplus, R.; Blanchon, L.; Fraga, M.; Didelot, C.; Morey, L.; Van Eynde, A.; Bernard, D.; Vanderwinden, J.M.; et al. The Polycomb group protein EZH2 directly controls DNA methylation. Nature 2006, 439, 871-874. [CrossRef]

52. Schlesinger, Y.; Straussman, R.; Keshet, I.; Farkash, S.; Hecht, M.; Zimmerman, J.; Eden, E.; Yakhini, Z.; Ben-Shushan, E.; Reubinoff, B.E.; et al. Polycomb-mediated methylation on Lys27 of histone H3 pre-marks genes for de novo methylation in cancer. Nat. Genet. 2007, 39, 232-236. [CrossRef]

53. Nyquist, M.D.; Corella, A.; Coleman, I.; De Sarkar, N.; Kaipainen, A.; Ha, G.; Gulati, R.; Ang, L.; Chatterjee, P.; Lucas, J.; et al. Combined TP53 and RB1 Loss Promotes Prostate Cancer Resistance to a Spectrum of Therapeutics and Confers Vulnerability to Replication Stress. Cell Rep. 2020, 31, 107669. [CrossRef] [PubMed] 
54. Liu, B.; Li, L.; Yang, G.; Geng, C.; Luo, Y.; Wu, W.; Manyam, G.C.; Korentzelos, D.; Park, S.; Tang, Z.; et al. PARP Inhibition Suppresses GR-MYCN-CDK5-RB1-E2F1 Signaling and Neuroendocrine Differentiation in Castration-Resistant Prostate Cancer. Clin. Cancer. Res. 2019, 25, 6839-6851. [CrossRef]

55. Kim, D.H.; Sun, D.; Storck, W.K.; Welker Leng, K.; Jenkins, C.; Coleman, D.J.; Sampson, D.; Guan, X.; Kumaraswamy, A.; Rodansky, E.S.; et al. BET Bromodomain Inhibition Blocks an AR-Repressed, E2F1-Activated Treatment-Emergent Neuroendocrine Prostate Cancer Lineage Plasticity Program. Clin. Cancer Res. 2021, 27, 4923-4936. [CrossRef]

56. Zhou, Z.; Flesken-Nikitin, A.; Corney, D.C.; Wang, W.; Goodrich, D.W.; Roy-Burman, P.; Nikitin, A.Y. Synergy of p53 and Rb deficiency in a conditional mouse model for metastatic prostate cancer. Cancer Res. 2006, 66, 7889-7898. [CrossRef] [PubMed]

57. Harris, S.L.; Levine, A.J. The p53 pathway: Positive and negative feedback loops. Oncogene 2005, 24, 2899-2908. [CrossRef]

58. Nevins, J.R. The Rb/E2F pathway and cancer. Hum. Mol. Genet. 2001, 10, 699-703. [CrossRef]

59. Akamatsu, S.; Wyatt, A.W.; Lin, D.; Lysakowski, S.; Zhang, F.; Kim, S.; Tse, C.; Wang, K.; Mo, F.; Haegert, A.; et al. The Placental Gene PEG10 Promotes Progression of Neuroendocrine Prostate Cancer. Cell Rep. 2015, 12, 922-936. [CrossRef] [PubMed]

60. Petroni, M.; Veschi, V.; Gulino, A.; Giannini, G. Molecular mechanisms of MYCN-dependent apoptosis and the MDM2-p53 pathway: An Achille's heel to be exploited for the therapy of MYCN-amplified neuroblastoma. Front. Oncol. $2012,2,141$. [CrossRef]

61. Beltran, H.; Rickman, D.S.; Park, K.; Chae, S.S.; Sboner, A.; MacDonald, T.Y.; Wang, Y.; Sheikh, K.L.; Terry, S.; Tagawa, S.T.; et al. Molecular characterization of neuroendocrine prostate cancer and identification of new drug targets. Cancer Discov. 2011, 1, 487-495. [CrossRef]

62. Hirano, D.; Okada, Y.; Minei, S.; Takimoto, Y.; Nemoto, N. Neuroendocrine differentiation in hormone refractory prostate cancer following androgen deprivation therapy. Eur. Urol. 2004, 45, 586-592. [CrossRef]

63. Svensson, C.; Ceder, J.; Iglesias-Gato, D.; Chuan, Y.C.; Pang, S.T.; Bjartell, A.; Martinez, R.M.; Bott, L.; Helczynski, L.; Ulmert, D.; et al. REST mediates androgen receptor actions on gene repression and predicts early recurrence of prostate cancer. Nucleic. Acids. Res. 2014, 42, 999-1015. [CrossRef]

64. Flores-Morales, A.; Bergmann, T.B.; Lavallee, C.; Batth, T.S.; Lin, D.; Lerdrup, M.; Friis, S.; Bartels, A.; Kristensen, G.; Krzyzanowska, A.; et al. Proteogenomic Characterization of Patient-Derived Xenografts Highlights the Role of REST in Neuroendocrine Differentiation of Castration-Resistant Prostate Cancer. Clin. Cancer Res. 2019, 25, 595-608. [CrossRef] [PubMed]

65. Labrecque, M.P.; Coleman, I.M.; Brown, L.G.; True, L.D.; Kollath, L.; Lakely, B.; Nguyen, H.M.; Yang, Y.C.; da Costa, R.M.G.; Kaipainen, A.; et al. Molecular profiling stratifies diverse phenotypes of treatment-refractory metastatic castration-resistant prostate cancer. J. Clin. Investig. 2019, 129, 4492-4505. [CrossRef] [PubMed]

66. Lee, J.K.; Phillips, J.W.; Smith, B.A.; Park, J.W.; Stoyanova, T.; McCaffrey, E.F.; Baertsch, R.; Sokolov, A.; Meyerowitz, J.G.; Mathis, C.; et al. N-Myc Drives Neuroendocrine Prostate Cancer Initiated from Human Prostate Epithelial Cells. Cancer Cell 2016, 29, 536-547. [CrossRef] [PubMed]

67. Berger, A.; Brady, N.J.; Bareja, R.; Robinson, B.; Conteduca, V.; Augello, M.A.; Puca, L.; Ahmed, A.; Dardenne, E.; Lu, X.; et al. $\mathrm{N}-$ Myc-mediated epigenetic reprogramming drives lineage plasticity in advanced prostate cancer. J. Clin. Investig. 2019, 129, 3924-3940. [CrossRef]

68. Strieder, V.; Lutz, W. E2F proteins regulate MYCN expression in neuroblastomas. J. Biol. Chem. 2003, 278, 2983-2989. [CrossRef]

69. Warner, S.L.; Bearss, D.J.; Han, H.; Von Hoff, D.D. Targeting Aurora-2 Kinase in Cancer1. Mol. Cancer Ther. $2003,2,589-595$.

70. Otto, T.; Horn, S.; Brockmann, M.; Eilers, U.; Schüttrumpf, L.; Popov, N.; Kenney, A.M.; Schulte, J.H.; Beijersbergen, R.; Christiansen, H. Stabilization of N-Myc is a critical function of Aurora A in human neuroblastoma. Cancer Cell 2009, 15, 67-78. [CrossRef]

71. Kivinummi, K.; Urbanucci, A.; Leinonen, K.; Tammela, T.L.; Annala, M.; Isaacs, W.B.; Bova, G.S.; Nykter, M.; Visakorpi, T. The expression of AURKA is androgen regulated in castration-resistant prostate cancer. Sci. Rep. 2017, 7, 1-11. [CrossRef]

72. Fraser, J.A.; Sutton, J.E.; Tazayoni, S.; Bruce, I.; Poole, A.V. hASH1 nuclear localization persists in neuroendocrine transdifferentiated prostate cancer cells, even upon reintroduction of androgen. Sci. Rep. 2019, 9, 1-15. [CrossRef] [PubMed]

73. Bishop, J.L.; Thaper, D.; Vahid, S.; Davies, A.; Ketola, K.; Kuruma, H.; Jama, R.; Nip, K.M.; Angeles, A.; Johnson, F. The Master Neural Transcription Factor BRN2 Is an Androgen Receptor-Suppressed Driver of Neuroendocrine Differentiation in Prostate Cancer. Cancer Discov. 2017, 7, 54-71. [CrossRef]

74. Vierbuchen, T.; Ostermeier, A.; Pang, Z.P.; Kokubu, Y.; Sudhof, T.C.; Wernig, M. Direct conversion of fibroblasts to functional neurons by defined factors. Nature 2010, 463, 1035-1041. [CrossRef]

75. Baca, S.C.; Takeda, D.Y.; Seo, J.H.; Hwang, J.; Ku, S.Y.; Arafeh, R.; Arnoff, T.; Agarwal, S.; Bell, C.; O'Connor, E.; et al. Reprogramming of the FOXA1 cistrome in treatment-emergent neuroendocrine prostate cancer. Nat. Commun. 2021, 12, 1979. [CrossRef]

76. Yasumizu, Y.; Rajabi, H.; Jin, C.; Hata, T.; Pitroda, S.; Long, M.D.; Hagiwara, M.; Li, W.; Hu, Q.; Liu, S. MUC1-C regulates lineage plasticity driving progression to neuroendocrine prostate cancer. Nat. Commun. 2020, 11, 1-13. [CrossRef]

77. Rajabi, H.; Joshi, M.D.; Jin, C.; Ahmad, R.; Kufe, D. Androgen receptor regulates expression of the MUC1-C oncoprotein in human prostate cancer cells. Prostate 2011, 71, 1299-1308. [CrossRef] [PubMed]

78. Bluemn, E.G.; Coleman, I.M.; Lucas, J.M.; Coleman, R.T.; Hernandez-Lopez, S.; Tharakan, R.; Bianchi-Frias, D.; Dumpit, R.F.; Kaipainen, A.; Corella, A.N. Androgen receptor pathway-independent prostate cancer is sustained through FGF signaling. Cancer Cell 2017, 32, 474-489.e476. [CrossRef] 
79. Su, W.; Han, H.H.; Wang, Y.; Zhang, B.; Zhou, B.; Cheng, Y.; Rumandla, A.; Gurrapu, S.; Chakraborty, G.; Su, J.; et al. The Polycomb Repressor Complex 1 Drives Double-Negative Prostate Cancer Metastasis by Coordinating Stemness and Immune Suppression. Cancer Cell 2019, 36, 139-155. [CrossRef]

80. Small, E.J.; Aggarwal, R.R.; Friedl, V.; Weinstein, A.; Thomas, G.V.; True, L.D.; Foye, A.; Beer, T.M.; Rettig, M.; Gleave, M. Intermediate atypical carcinoma (IAC): A discrete subtype of metastatic castration-resistant prostate cancer (mCRPC) suggesting that treatment-associated small cell/neuroendocrine prostate cancer (t-SCNC) may evolve from mCRPC adenocarcinoma (adeno)-Results from the SU2C/PCF/AACR West Coast Prostate Cancer Dream Team (WCDT). J. Clin. Oncol. 2020, $38,158$.

81. Mosquera, J.M.; Beltran, H.; Park, K.; MacDonald, T.Y.; Robinson, B.D.; Tagawa, S.T.; Perner, S.; Bismar, T.A.; Erbersdobler, A.; Dhir, R. Concurrent AURKA and MYCN gene amplifications are harbingers of lethal treatmentrelated neuroendocrine prostate cancer. Neoplasia 2013, 15, 1-IN4. [CrossRef] [PubMed]

82. Beltran, H.; Romanel, A.; Conteduca, V.; Casiraghi, N.; Sigouros, M.; Franceschini, G.M.; Orlando, F.; Fedrizzi, T.; Ku, S.Y.; Dann, E.; et al. Circulating tumor DNA profile recognizes transformation to castration-resistant neuroendocrine prostate cancer. J. Clin. Investig. 2020, 130, 1653-1668. [CrossRef] [PubMed]

83. Denmeade, S.R.; Wang, H.; Agarwal, N.; Smith, D.C.; Schweizer, M.T.; Stein, M.N.; Assikis, V.; Twardowski, P.W.; Flaig, T.W.; Szmulewitz, R.Z.; et al. TRANSFORMER: A Randomized Phase II Study Comparing Bipolar Androgen Therapy Versus Enzalutamide in Asymptomatic Men With Castration-Resistant Metastatic Prostate Cancer. J. Clin. Oncol. 2021, 39, $1371-1382$. [CrossRef] [PubMed] 